\title{
Analysis of Reserves in Multiple Life Insurance using Copula
}

\author{
Issac Lee ${ }^{a}$, Hangsuck Lee ${ }^{1, b}$, Hyun Tae Kim ${ }^{c}$ \\ ${ }^{a}$ Department of Actuarial Science, Sungkyunkwan University, Korea \\ ${ }^{b}$ Department of Actuarial Science/Mathematics,Sungkyunkwan University, Korea \\ ${ }^{c}$ Department of Applied Statistics, Yonsei University, Korea
}

\begin{abstract}
We study the dependence between the insureds in multiple-life insurance contracts. With the future lifetimes of the insureds modeled as correlated random variables, both premium and reserve are different from those under independence. In this paper, Gaussian copula is used to impose the dependence between the insureds with Gompertz marginals. We analyze the change of the reserves of standard multiple-life insurance contracts at various dependence levels. We find that the reserves based on the assumption of dependent lifetimes are quite different for some contracts from those under independence as its correlation increase, which elucidate the importance of the dependence model in multiple-life contingencies in both theory and practice.
\end{abstract}

Keywords: Gaussian copula, reserves analysis, multiple life insurance, joint life survival function.

\section{Introduction}

Multiple-life insurance contract involve more than one life and pay benefits depending on the multiple life status of the insured lives. The future lifetimes (or times-till-death) of the lives involved in multiple-life contracts have been considered to be independent in traditional actuarial literature. More recently, the independence assumption has been relaxed (e.g., Frees et al., 1996) and there have been attempts to impose dependence structure via multivariate distributions or copulas. Dependence between lives in joint life contracts can arise from common accidents or life style. The assumption of independence may lead to an inadequate actuarial pricing and reserve due to insurance contracts premiums written as expected values for function of the future lifetime random variables.

The underlying dependence structure plays a crucial role in multivariate models for the calculation of many distributional quantities that include the moments. The copula developed by Sklar (1973) has been applied in many academic fields. Zhang and Singh (2006) analyze a bivariate distribution of flood peak and volume using a copula method in the civil engineering field. Schölzel and Friederichs (2008) studied various multivariate random variables in climate research such as the bivariate distribution of average daily precipitation and minimum temperature or bivariate distribution of daily wind maxima between two subway stations. Onken et al. (2009) adopted copula method to analyze simultaneous spike-counts in biology. In quantitative finance field, $\mathrm{Li}$ (2000), one of famous actuaries in the world, introduces a new method of a pricing framework for credit risk derivatives that created a sensation among practitioners in the financial markets. Copulas are now traditionally applied by many scholars in the actuarial science field. Frees et al. (1996) evaluate a multiple life annuity value using a Frank copula; in addition, Shemyakin and Youn (2006) analyzed a joint last survivor insurance contract

\footnotetext{
${ }^{1}$ Corresponding author: Associate Professor, Department of Actuarial Science/Mathematics, Sungkyunkwan University, 25-2, Sungkyunkwan-ro, Jongno-gu, Seoul 110-745, Korea. E-mail: hangsuck@skku.edu
} 
using a copula model. Shi and Frees (2011) and de Jong (2012) selected a copula method to model the dependency of loss triangles and analyze general insurance reserves.

The present article investigates the impact of the dependence between the mortalities in multiple life contracts. We use a Gaussian copula to model the dependence with the marginals modelled by Gompertz mortality. Both pricing and the reserving under this copula model are examined, with emphasizing the latter. The article is organized as follows. In Chapter 2, we review the random variables used in joint life models and introduce a Gaussian copula used to calculate the premiums and reserves of joint life contracts under dependence. We also present an alternative explanation for the relationship between multiple-life random variables analyzed by Youn et al. (2002) and reconfirm their results with a copula method. In Chapter 3, we study some reserves formulae under independence. Chapter 4 shows how the copula model alters the traditional reserve values calculated under independence. In particular, we analyze the reserves of four standard multiple-life insurance contracts which serve as basic building blocks for contract analyses, which is the topic of Chapter 5. Most of the backgrounds of insurance reserves are based on Bowers et al. (1997) and Dickson et al. (2009), and the backgrounds of copulas on Nelsen (2006) and Cherubini et al. (2004).

\section{Multiple Life Insurance and Copula}

\subsection{Random variables for multiple-life status}

Following the notations from Bowers et al. (1997), we denote the continuous random future lifetime of a male aged $x$ by $T_{x}$. In particular, we further denote $T_{0}=X$, a random variable representing the future lifetime of a male at birth. Then $T_{x}$ can be written as a conditional random variable

$$
T_{x}=X-x \mid X>x
$$

Similarly, we can define $T_{y}$ and $Y$ for a female aged $y$. In the spousal mortality context, we define the multiple life random variables $T_{x y}$ and $T_{\overline{x y}}$ by

$$
T_{x y}=\min \left(T_{x}, T_{y}\right), \quad T_{\overline{x y}}=\max \left(T_{x}, T_{y}\right) .
$$

Note that both $T_{x y}$ and $T_{\overline{x y}}$ assume $(x)$ and $(y)$ are still alive at that time. We can also write these random variables as

$$
T_{x y}=\min (X-x|X>x, Y-y| Y>y)
$$

and

$$
T_{\overline{x y}}=\max (X-x|X>x, Y-y| Y>y) .
$$

From the definition above, we have a well-known identity

$$
T_{x y}+T_{\overline{x y}}=T_{x}+T_{y}
$$

without mentioning any dependence assumption between $(x)$ and $(y)$. Furthermore, standard textbooks such as Bowers et al. (1997) also gives us

$$
{ }_{t} p_{x y}+{ }_{t} p_{\overline{x y}}={ }_{t} p_{x}+{ }_{t} p_{y}
$$


and

$$
\bar{A}_{x y}+\bar{A}_{\overline{x y}}=\bar{A}_{x}+\bar{A}_{y} .
$$

Equation (2.7) is widely used to calculate multiple-life insurance premiums. However, Youn et al. (2002) show that, equation (2.5) is not precisely true if independence assumption is relaxed and equations (2.6) and (2.7) do not hold. They verify this using a Hougaard copula with Weibull marginals. Actually, we can use a slightly different argument from Youn et al. (2002) to prove that equation (2.6) fails to hold in general as follows.

The left side of (2.6) is written as

$$
\begin{aligned}
{ }_{t} p_{x y}+{ }_{t} p_{\overline{x y}} & =P[X>x+t \text { and } Y>y+t \mid X>x, Y>y]+P[X>x+t \text { or } Y>y+t \mid X>x, Y>y] \\
& =P[X>x+t \mid X>x, Y>y]+P[Y>y+t \mid X>x, Y>y] \\
& =P\left[T_{x}>t \mid T_{y}>0\right]+P\left[T_{y}>t \mid T_{x}>0\right],
\end{aligned}
$$

where the second equality comes from the probability set operation $P[A \cup B]=P[A]+P[B]-P[A \cap B]$. The right side of (2.6) is simply

$$
\begin{aligned}
{ }_{t} p_{x}+{ }_{t} p_{y} & =P[X>x+t \mid X>x]+P[Y>y+t \mid Y>y] \\
& =P\left[T_{x}>t\right]+P\left[T_{y}>t\right] .
\end{aligned}
$$

Hence it is clear that the conditions given inside (2.8) and (2.9) are not identical. When $X$ and $Y$ are independent, (2.8) reduces to (2.9), and both yield an identical value. This discrepancy is necessarily carried over to (2.7) as well. To summarize, the proper evaluation of the left sides of (2.6) and (2.7), or multiple life random variables in general, requires the presence of precondition on the other variable, that is,

$$
T_{x} \mid T_{y}>0 \text { and } T_{y} \mid T_{x}>0 .
$$

The correct expression of (2.5) that holds true in general is

$$
T_{x y}+T_{\overline{x y}}=T_{x}\left|T_{y}>0+T_{y}\right| T_{x}>0 .
$$

\subsection{Gaussian copula}

Let $F$ be a $d$-dimensional joint distribution function (d.f.) with marginals $F_{1}, \ldots, F_{d}$. The theorem of Sklar (1973) asserts that, when the marginals are continuous, a copula $C$ with

$$
F\left(x_{1}, \ldots, x_{d}\right)=C\left[F_{1}\left(x_{1}\right), \ldots, F_{d}\left(x_{d}\right)\right]
$$

exists uniquely for every $x_{1}, \ldots, x_{d} \in \mathbb{R}$. The copula itself therefore can be obtained from (2.12) for all $u=\left(u_{1}, \ldots, u_{d}\right) \in[0,1]^{d}$ as

$$
C\left(u_{1}, \ldots, u_{d}\right)=F\left[F_{1}^{-1}\left(u_{1}\right), \ldots, F_{d}^{-1}\left(u_{d}\right)\right] .
$$

To this extent, we focus on the Gaussian copula with $d=2$, commonly called the Bivariate Gaussian copula

$$
C(u, v)=\int_{-\infty}^{\Phi^{-1}(u)} \int_{-\infty}^{\Phi^{-1}(v)} \frac{1}{2 \pi \sqrt{1-\rho^{2}}} \exp \left\{-\frac{x^{2}-2 \rho x y+y^{2}}{2\left(1-\rho^{2}\right)}\right\} d x d y, \quad(u, v) \in[0,1]^{2},
$$


where $\Phi$ is the d.f. of the standard normal distribution.

We calculate multiple life reserves where the dependence structure between two lives are modelled by a Bivariate Gaussian copula with two Gompertz marginals. In this article, we adopt a Gaussian copula to calculate the reserves because only a Gaussian copula allows an arbitrary correlation matrix yet still lends itself to efficient simulation techniques (see Wang, 1998). Gompertz distribution function of $T_{x}$ is used to model the future lifetimes of each insured person aged $x$. Gompertz d.f. of $T_{x}$ is given by

$$
F_{T_{x}}(t)=1-\exp \left[e^{\frac{(x-m)}{\sigma}}\left(1-e^{\frac{t}{\sigma}}\right)\right],
$$

where the mode, $m$, and the scale measure, $\sigma$, are parameters. This formula is suggested by Carriere (1994), which is transformed from the original Gompertz d.f. for the straightforward estimation of parameters. Then, from (2.12), we may write the joint d.f. of the future lifetimes of two lives as

$$
\begin{aligned}
& F_{T_{x}, T_{y}}\left(t_{1}, t_{2}\right)=C\left[F_{T_{x}}\left(t_{1}\right), F_{T_{y}}\left(t_{2}\right)\right] \\
& =\int_{-\infty}^{\Phi^{-1}\left(F_{T_{x}}\left(t_{1}\right)\right)} \int_{-\infty}^{\Phi^{-1}\left(F_{T_{y}}\left(t_{2}\right)\right)} \frac{1}{2 \pi \sqrt{1-\rho^{2}}} \exp \left\{-\frac{x^{2}-2 \rho x y+y^{2}}{2\left(1-\rho^{2}\right)}\right\} d x d y .
\end{aligned}
$$

Note that the dependence between $T_{x}$ and $T_{y}$ has been created via the correlation $\rho$ embedded in the Gaussian copula. When $\rho=0,(2.16)$ reduces to the classical independent case where the joint d.f. becomes simply the product the two marginals d.f.'s

$$
F_{T_{x}, T_{y}}\left(t_{1}, t_{2}\right)=F_{T_{x}}\left(t_{1}\right) F_{T_{y}}\left(t_{2}\right)
$$

which is the case for the classical independent multiple life framework.

\subsection{Re-confirmation of the multiple life equalities}

Using actual Korean experienced life tables, we confirm the failure of equation (2.7) using a bivariate Gaussian copula with Gompertz marginals. The parameters of Gompertz marginals are estimated by the least square method (see Lee et al., 2013), and their values are the male's parameters $m_{1}=85.69$, $\sigma_{1}=9.57$, and female's parameters $m_{2}=90.70, \sigma_{2}=8.01$. For the calculation, the age of both males and females are set at 40 and a force of interest at 0.12 , which are arbitrarily fixed values. We set the number of simulation to hundred thousand to keep the simulation errors under $5 \times 10^{-4}$ since the expected value of the Monte Carlo method always involves errors. After this section, when the insurance contracts are evaluated using the Monte Carlo method, a reference sample size is a hundred thousand.

Table 1(and Figure 1 for graph) ascertains that equation (2.7) fails except for the independence case, corresponding to $\rho=0$ in the Gaussian copula. In particular, Figure 1 illustrates that the difference between left and right hand sides of (2.7) increases rapidly as the correlation gets close to 1. As equation (2.7) fails to hold under dependence, one needs to find an alternative way to evaluate the left side of (2.7). For this, we first derive the following identity relationship from equation (2.11):

$$
v^{T_{x y}}+v^{T_{\overline{x y}}}=v^{T_{x}}\left|T_{y}>0+v^{T_{y}}\right| T_{x}>0 .
$$

Then we get the expected present value by taking expectation to the both sides of the equation as

$$
\bar{A}_{x y}+\bar{A}_{\overline{x y}}=\mathbb{E}\left[v^{T_{x}} \mid T_{y}>0\right]+\mathbb{E}\left[v^{T_{y}} \mid T_{x}>0\right] .
$$




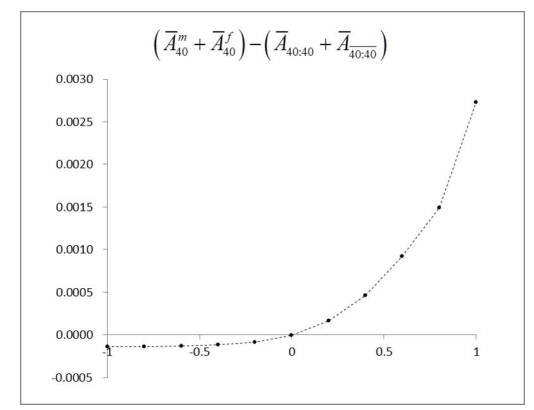

Figure 1: Failure of equation (2.7) under dependence. Horizontal axis is correlation

Table 1: Failure of equation (2.7) under dependence

\begin{tabular}{cccccccc}
\hline \hline$\rho$ & $\bar{A}_{40}^{m}$ & $\bar{A}_{40}^{f}$ & $\bar{A}_{40: 40}$ & $\bar{A}_{40: 40}$ & $\bar{A}_{40}^{m}+\bar{A}_{40}^{f}$ & $\bar{A}_{40: 40}+\bar{A}_{40: 40}$ & $(\mathrm{~A})-(\mathrm{B})$ \\
\hline-1.0 & 0.0259 & 0.0117 & 0.0355 & 0.0023 & 0.0376 & 0.0378 & -0.0001 \\
-0.8 & 0.0260 & 0.0116 & 0.0352 & 0.0025 & 0.0376 & 0.0377 & -0.0001 \\
-0.6 & 0.0262 & 0.0115 & 0.0351 & 0.0028 & 0.0377 & 0.0379 & -0.0001 \\
-0.4 & 0.0260 & 0.0116 & 0.0346 & 0.0031 & 0.0376 & 0.0378 & -0.0001 \\
-0.2 & 0.0262 & 0.0115 & 0.0343 & 0.0036 & 0.0378 & 0.0379 & -0.0001 \\
0.0 & 0.0263 & 0.0116 & 0.0338 & 0.0041 & 0.0379 & 0.0379 & 0.0000 \\
0.2 & 0.0262 & 0.0116 & 0.0328 & 0.0049 & 0.0379 & 0.0377 & 0.0002 \\
0.4 & 0.0260 & 0.0115 & 0.0314 & 0.0057 & 0.0376 & 0.0371 & 0.0005 \\
0.6 & 0.0259 & 0.0116 & 0.0298 & 0.0068 & 0.0375 & 0.0366 & 0.0009 \\
0.8 & 0.0261 & 0.0116 & 0.0280 & 0.0082 & 0.0377 & 0.0362 & 0.0015 \\
1.0 & 0.0262 & 0.0116 & 0.0262 & 0.0088 & 0.0378 & 0.0350 & 0.0027 \\
\hline \hline
\end{tabular}

Table 2: Verification of equation (2.19) under general condition

\begin{tabular}{|c|c|c|c|c|c|c|c|}
\hline$\rho$ & $\begin{array}{c}(\mathrm{A}) \\
\mathbb{E}\left[v^{T_{40}^{m}} \mid T_{40}^{f}>0\right]\end{array}$ & $\begin{array}{c}(\mathrm{B}) \\
\mathbb{E}\left[v^{T_{40}^{f}} \mid T_{40}^{m}>0\right]\end{array}$ & $\begin{array}{c}(\mathrm{C}) \\
\bar{A}_{40: 40}\end{array}$ & $\begin{array}{c}\text { (D) } \\
\overline{A_{40: 40}}\end{array}$ & $\begin{array}{c}(\mathrm{E}) \\
(\mathrm{A})+(\mathrm{B})\end{array}$ & $\begin{array}{c}(\mathrm{F}) \\
(\mathrm{C})+(\mathrm{D})\end{array}$ & $(\mathrm{E})-(\mathrm{F})$ \\
\hline-1.0 & 0.0262 & 0.0117 & 0.0357 & 0.0023 & 0.0379 & 0.0379 & 0 \\
\hline-0.8 & 0.0260 & 0.0117 & 0.0352 & 0.0025 & 0.0377 & 0.0377 & 0 \\
\hline-0.6 & 0.0260 & 0.0117 & 0.0349 & 0.0028 & 0.0377 & 0.0377 & 0 \\
\hline-0.4 & 0.0260 & 0.0116 & 0.0345 & 0.0031 & 0.0376 & 0.0376 & 0 \\
\hline-0.2 & 0.0263 & 0.0116 & 0.0343 & 0.0036 & 0.0379 & 0.0379 & 0 \\
\hline 0.0 & 0.0263 & 0.0115 & 0.0337 & 0.0041 & 0.0378 & 0.0378 & 0 \\
\hline 0.2 & 0.0261 & 0.0114 & 0.0327 & 0.0048 & 0.0375 & 0.0375 & 0 \\
\hline 0.4 & 0.0259 & 0.0113 & 0.0315 & 0.0057 & 0.0372 & 0.0372 & 0 \\
\hline 0.6 & 0.0255 & 0.0109 & 0.0297 & 0.0067 & 0.0364 & 0.0364 & 0 \\
\hline 0.8 & 0.0259 & 0.0104 & 0.0281 & 0.0082 & 0.0363 & 0.0363 & 0 \\
\hline 1.0 & 0.0262 & 0.0089 & 0.0262 & 0.0089 & 0.0350 & 0.0350 & 0 \\
\hline
\end{tabular}

Table 2 presents the values of equation (2.19) for various correlations. Under the independent assumption, the equation (2.19) turns into equation (2.7) because the life status of a spouse does not affect the calculation of the expected present value.

\subsection{Simulating dependent lifetimes using Gaussian copula}

The algorithm in this section plays an important role to calculate multiple life insurance reserves under certain given conditions (see Cherubini et al. (2004) for an in-depth look at the algorithms explained here). 
Table 3: Generating a correlated random vector under Gaussian copula

\begin{tabular}{ccc}
\hline \hline $\begin{array}{c}\text { Correlated standard } \\
\text { Normal vector }\end{array}$ & $\begin{array}{c}\text { Convert to uniform } \\
\text { random vector }\end{array}$ & $\begin{array}{c}\text { Transform to } \\
\text { marginal distribution }\end{array}$ \\
\hline$\left(\begin{array}{l}z_{1} \\
z_{2}\end{array}\right)$ & $\left(\begin{array}{l}\Phi\left(z_{1}\right) \\
\Phi\left(z_{2}\right)\end{array}\right) \rightarrow\left(\begin{array}{l}u_{1} \\
u_{2}\end{array}\right)$ & $\left(\begin{array}{c}F_{T_{x}}^{-1}\left(u_{1}\right) \\
F_{T_{y}}^{-1}\left(u_{2}\right)\end{array}\right) \longrightarrow\left(\begin{array}{c}t_{1} \\
t_{2}\end{array}\right)$ \\
\hline \hline
\end{tabular}

Many distributional quantities arising from (2.16) are obtained from a Monte Carlo simulation method, we now briefly discuss how random samples are drawn both conditionally and unconditionally in the presence of the Gaussian copula. Let $\left(Z_{1}, Z_{2}\right)$ be a bivariate standard normal random variable with density function

$$
f\left(z_{1}, z_{2}\right)=\frac{1}{2 \pi \sqrt{1-\rho^{2}}} \exp \left\{-\frac{z_{1}^{2}-2 \rho z_{1} z_{2}+z_{2}^{2}}{2\left(1-\rho^{2}\right)}\right\},
$$

where $-\infty<z_{1}, z_{2}<\infty$ and $-1 \leq \rho \leq 1$. It is well-known that marginal random variables $Z_{1}$ and $Z_{2}$ are also standard normal distributed; therefore, the conditional distribution of $Z_{1}$ given $Z_{2}=z_{2}$ :

$$
Z_{1} \mid Z_{2}=z_{2} \sim N\left(\rho z_{2},\left(1-\rho^{2}\right)\right) .
$$

See, e.g., Ross (2006), for the properties of the normal distribution. This conditional distribution result allows a convenient way to simulate samples from the bivariate standard normal distribution in two steps as follows.

1. First, draw two random observations from the independent standard normal, and denote these $w_{1}$ and $w_{2}$. Set $z_{2}=w_{2}$.

2. In the second step, simulate a sample from the conditional distribution (2.21). This can be done by setting $z_{1}=\rho w_{2}+w_{1} \sqrt{\left(1-\rho^{2}\right)}$, where $w_{2}$ is from the first step.

The resulting $\left(z_{1}, z_{2}\right)$ is then a simulated sample from the bivariate standard normal distribution with correlation $\rho$.

We now describe how to generate a random vector $\left(t_{1}, t_{2}\right)$ from the bivariate Gaussian copula (2.14) with marginal d.f.'s $F_{T_{x}}\left(t_{1}\right)$ and $F_{T_{y}}\left(t_{2}\right)$, as stated in (2.16). The procedure requires first to simulate a sample from the copula function (2.12) and then transform the obtained (copula) sample to the corresponding marginals via its inverse d.f. This method is actually quite general and can be applied to any copula and marginals. Table 3 describes the specific sampling steps for our choice of model. All distributional quantities (such as the expectation value and higher moments) can be calculated from this Monte-Carlo method.

In addition to the unconditional sampling explained above, we also need the conditional sampling procedure in the copula model. For example, later we will need to determine $\mathbb{E}\left[T_{x} \mid T_{y}<t_{2}\right]$ for multiple life reserves, which in turn requires an efficient way to sample from conditional random variables, such as $T_{x} \mid T_{y}<t_{2}$ or $T_{y} \mid T_{x}<t_{1}$. Below we describe the conditional sampling procedure from the Gaussian copula model in several steps where the conditional random variable of interest is $T_{x} \mid T_{y}<t_{2}$; in addition, similar arguments can be made for other conditional random variables.

1. Generate $u_{1}$ and $u_{2}$ independently from the uniform distribution

2. Calculate $k=F_{T_{y}}\left(t_{2}\right)$ and obtain $u_{2} k$, which is always less than $k$. This step effectively generates samples from area $T_{y}<t_{2}$ 
Table 4: Generating the conditional random sample using a Gaussian copula

\begin{tabular}{cccc}
\hline \hline $\begin{array}{c}\text { Determine } k \\
\text { generate } u_{1}, u_{2}\end{array}$ & $\begin{array}{c}\text { Calculate standard } \\
\text { Normal value }\end{array}$ & $\begin{array}{c}\text { Determine value } \\
\text { of } Z_{1} \mid Z_{2}=z_{2}\end{array}$ & $\begin{array}{c}\text { Convert to marginal } \\
\text { distribution of } T_{x} \mid T_{y}<t_{2}\end{array}$ \\
\hline$k=F_{T_{y}}\left(t_{2}\right)$, & $z_{2}=\Phi^{-1}\left(k u_{2}\right)$ & $z_{1} \mid z_{2}=w_{1} \sqrt{\left(1-\rho^{2}\right)}+\rho z_{2}$ & $t_{1}=F_{T_{x}}^{-1}\left[\Phi\left(z_{1} \mid z_{2}\right)\right]$ \\
$u_{1}, u_{2}$ & $w_{1}=\Phi^{-1}\left(u_{1}\right)$ & & \\
\hline
\end{tabular}

3. Let $z_{2}=\Phi^{-1}\left(u_{2} k\right)$, a standard normal sample. Then, from (2.21), we see that

$$
Z_{1} \mid Z_{2}=z_{2} \sim N\left(\rho z_{2},\left(1-\rho^{2}\right)\right) .
$$

4. Set $w_{1}=\Phi^{-1}\left(u_{1}\right)$ using the inverse transform. Then $w_{1}$ is a sample from the standard Normal distribution.

5. Get a random sample from the conditional distribution of $Z_{1} \mid Z_{2}=z_{2}$ using (2.21):

$$
z_{1} \mid z_{2}=\rho z_{2}+w_{1} \sqrt{\left(1-\rho^{2}\right)} .
$$

6. Finally, convert $z_{1} \mid z_{2}$ to find the $t_{1} \mid t_{2}$ using

$$
t_{1} \mid t_{2}=F_{T_{x}}^{-1}\left[\Phi\left(z_{1} \mid z_{2}\right)\right] .
$$

Here $t_{1} \mid t_{2}$ is a sample from the conditional random variable of interest $T_{x} \mid T_{y}<t_{2}$.

By repeating the steps above one can obtain random samples to determine various values of the conditional distributional quantities. Table 4 presents a summarized version of this algorithm.

\section{Formulae of Reserves for Multiple Life Contracts}

\subsection{Multiple life reserves}

For a life insurance contract issued at time 0 , its reserve is generally defined by the conditional expectation of loss random variable at time $t>0$ given that the insured is alive at that time. We denote a loss random variable at time $t$ by ${ }_{t} L$ that represents the difference between the present value of the future benefit the insured will receive and the present value of the future premiums the insured will pay. For a contract issued to a single life aged $x$, the reserve at time $t$ is therefore defined as

$$
{ }_{t} V=\mathbb{E}\left[{ }_{t} L \mid T_{x}>t\right] .
$$

However, things are slightly different for the reserve of multiple life case. Let us assume that two people (or a couple) bought a multiple life contract. Since there are two lives instead of one, we need to consider possible cases to determine the reserve at time $t$, with the first case being both $(x)$ and (y) alive, and second being only one of the two alive. The loss random variable at time $t$ then can be written using standard actuarial notations as follows.

$$
\begin{aligned}
& \text { case 1: }{ }_{t} L \mid T_{x y}>t, \\
& \text { case 2: }{ }_{t} L \mid T_{x}>t, T_{y} \leq t, \\
& \text { case 3: }{ }_{t} L \mid T_{y}>t, T_{x} \leq t .
\end{aligned}
$$

Depending on the cases, the loss random variables give rise to the different formulae of reserves shown in the next chapter. 


\subsection{Multiple life insurance}

We start by considering the reserve value of a fully continuous joint life insurance of 1 on the aged $x$ and $y$. In this contract, the benefit is paid at the first death; thus, only the case that both insured people are alive needs to be considered. The future loss random variable at time $t$ is

$$
{ }_{t} L=v^{\left(T_{x y}-t\right)} .
$$

Just as in equation (3.1), the reserve at time $t$ is the conditional expectation of loss random variable given that both insured are alive at $t$. That is,

$$
{ }_{t} V\left(\bar{A}_{x y}\right)=\mathbb{E}\left[{ }_{t} L \mid T_{x y}>t\right]=\bar{A}_{x+t, y+t} .
$$

Next, we consider the reserve of the last survivor insurance with a benefit amount 1 payable immediately on the second death between the two lives. The future loss random variable at time $t$ is then

$$
{ }_{t} L=v^{\left(T_{\overline{x y}}-t\right)} .
$$

However, unlike the joint life insurance case considered previously, multiple cases as in (3.2)-(3.4) should be considered separately for proper reserve calculations. At the future time $t$, both $(x)$ and $(y)$ could be alive or one of them could have already died. Therefore, three cases of reserve values should be calculated:

$$
\begin{aligned}
& { }_{t} V\left(\bar{A}_{\overline{x y}}\right)^{c 1}=\mathbb{E}\left[v^{\left(T_{\overline{x y}}-t\right)} \mid T_{x y}>t\right]=\bar{A}_{\overline{x+t, y+t}}, \\
& { }_{t} V\left(\bar{A}_{\overline{x y}}\right)^{c 2}=\mathbb{E}\left[v^{\left(T_{\overline{x y}}-t\right)} \mid T_{x}>t, T_{y} \leq t\right]=\mathbb{E}\left[v^{T_{x+t}} \mid T_{y} \leq t\right], \\
& { }_{t} V\left(\bar{A}_{\overline{x y}}\right)^{c 3}=\mathbb{E}\left[v^{\left(T_{\overline{x y}}-t\right)} \mid T_{y}>t, T_{x} \leq t\right]=\mathbb{E}\left[v^{T_{y+t}} \mid T_{x} \leq t\right],
\end{aligned}
$$

where superscripts of equations, $c 1, c 2$ and $c 3$ represent the status of its loss random variable.

\subsection{Multiple life annuity}

We consider two standard types of multiple life annuities (joint life and last survivor annuities) in this subsection. A joint life annuity pays continuously at a rate of 1 per year while both insureds are still alive. The future loss random variable at time $t$ of this contract is

$$
{ }_{t} L=\frac{1-v^{\left(T_{x y}-t\right)}}{\delta} .
$$

The reserve of this joint life annuity at time $t$ is defined as the conditional expectation of (3.11) given that both $x$ and $y$ are still alive at time $t$ :

$$
{ }_{t} V\left(\bar{a}_{x y}\right)=E\left[\frac{1-v^{\left(T_{x y}-t\right)}}{\delta} \mid T_{x y}>t\right]=\bar{a}_{x+t, y+t} .
$$

A last survivor annuity means a life annuity pays continuously at a rate of 1 per year while at least one of the two is still alive. Similar to joint life annuity, loss random variable at time $t$ is

$$
{ }_{t} L=\frac{1-v^{\left(T_{\overline{x y}}-t\right)}}{\delta} .
$$


Table 5: Combination of the premium $\rho$ and the reserves $\rho$

\begin{tabular}{|c|c|c|c|}
\hline & & \multicolumn{2}{|c|}{ Premium process } \\
\hline & & Indep. & Dep. \\
\hline \multirow[b]{2}{*}{ Reserves process } & Indep. & ${ }_{t} V(0,0)$ & ${ }_{t} V(0, \rho)$ \\
\hline & Dep. & ${ }_{t} V(\rho, 0)$ & ${ }_{t} V(\rho, \rho)$ \\
\hline
\end{tabular}

Like the last survivor life insurance, the reserve of last survivor annuity is obtained separately for three cases:

$$
\begin{aligned}
& { }_{t} V\left(\bar{a}_{\overline{x y}}\right)^{c 1}=E\left[\frac{1-v^{\left(T_{\overline{x y}}-t\right)}}{\delta} \mid T_{x y}>t\right]=\bar{a}_{\overline{x+t, y+t}}, \\
& { }_{t} V\left(\bar{a}_{\overline{x y}}\right)^{c 2}=E\left[\frac{1-v^{\left(T_{\overline{x y}}-t\right)}}{\delta} \mid T_{x}>t, T_{y} \leq t\right]=\frac{1-E\left[v^{T_{x+t}} \mid T_{y} \leq t\right]}{\delta}, \\
& { }_{t} V\left(\bar{a}_{\overline{x y}}\right)^{c 3}=E\left[\frac{1-v^{\left(T_{\overline{x y}}-t\right)}}{\delta} \mid T_{y}>t, T_{x} \leq t\right]=\frac{1-E\left[v^{T_{y+t}} \mid T_{x} \leq t\right]}{\delta},
\end{aligned}
$$

where superscripts of equations, $c 1, c 2$ and $c 3$, represent the statuses of its loss random variable.

\section{Analysis of Reserves under Dependent Assumption}

\subsection{Reserves changes when there is dependency}

Reserves at time $t$ are conditional expectations. Therefore, some reserve values can be materially different when the dependency exists. In this spirit, we may consider four different situations depending on whether the dependence is present or not, and the process of interest is pricing or reserving (see Table 5). We have included the pricing dependence parameter, $\rho_{\text {pricing }}$, because the correlation affects the premium calculation (see Section 2). In Table 5 we denote reserve of the insurance contract at time $t$ as

$$
{ }_{t} V\left(\rho_{\text {reserves }}, \rho_{\text {pricing }}\right) \text {. }
$$

In the table, for example, ${ }_{t} V(\rho, 0)$ means that we assume dependence for the reserve, but with the premium derived from independence.

\subsection{Reserves of multiple life insurance: both the insured alive}

The reserves of joint life insurance contracts, assuming that the insureds pay a single premium at issue and receives a benefit of 1 increases from 0.2 to 1 over time. Figure 2 illustrates the reserve values during the contract period. Note that there is a jump at time zero. The reserves are zero at time 0 (determined by an equivalence premium principle); however, the values jump from zero and are affected by $\rho$ in the reserve calculation.

The reserves of joint life insurance decrease as $\rho$ increases. In the left panel of Figure 2, however, the gaps between independent reserve and dependent reserves reduce as time passes. This tendency can be explained by two reasons. The first reason is an aging effect. The dependence effect decreases gradually as one gets older because the magnitude of the mortality becomes large enough at higher ages to outweigh the dependence effect. As time passes, the insured gets older and the reserve value gets closer to the independent reserve over time. Second, all reserves have the same terminal value. Its terminal value must be 1 regardless of the correlation since joint life insurance is a type of whole life 

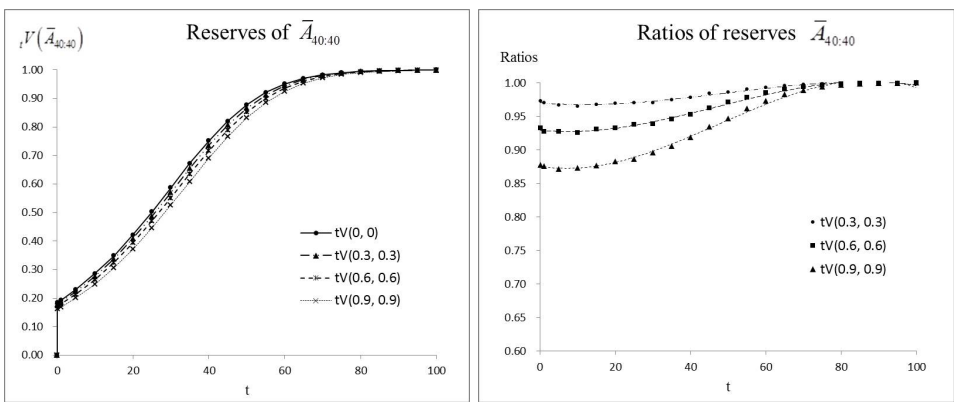

Figure 2: Reserves and ratio of reserves of $\bar{A}_{40: 40}$ (Assumption: $T_{40}>t, T_{40}>t$ )

Table 6: Reserves and ratio of reserves of $\bar{A}_{40: 40}$ (Assumption: $T_{40}>t, T_{40}>t$ )

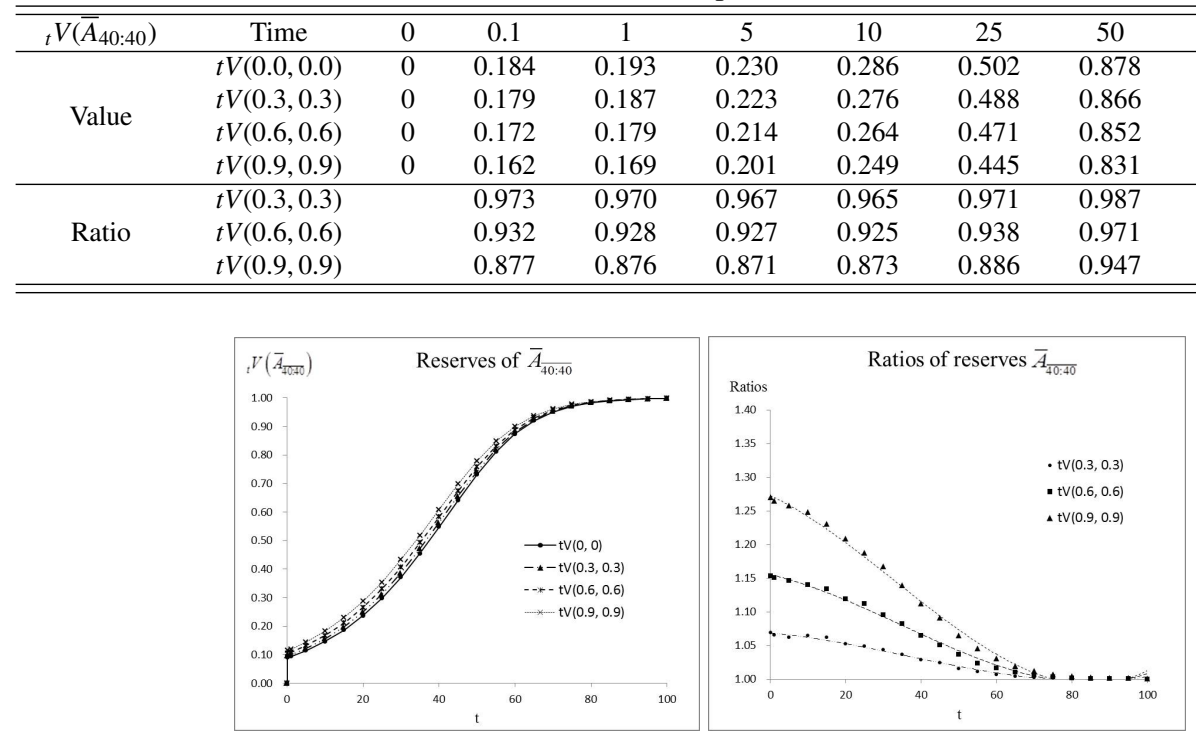

Figure 3: Reserves and ratio of reserves of $\bar{A} \overline{40: 40}\left(\right.$ Assumption: $T_{40}>t, T_{40}>t$ )

insurance contracts. The right panel of Figure 2 shows this tendency using a ratio dependent reserves to independent reserves as its measure.

Frees et al. (1996) estimated the value 0.49 of Spearman's correlation coefficient from the multiple insurance data set. The estimate 0.49 indicates a strong statistical dependence between the husband's and wife's mortality. According to Fang et al. (2002), Spearman's correlation coefficient is almost the same as the parameter of Gaussian copula. Table 6 presents some selected reserve values. In Table 6 , note that reserves of $\rho=0.6$ at time 10 is proportional to $92.5 \%$ compared with the value calculated under independent assumption.

The reserves of the last survivor insurance contracts rise from 0.1 to 1 , given that both insured people are still alive at time $t$. Compared with the reserves of the joint life insurance, the reserves of last survivor insurance increase as the dependence gets stronger. The left panel of Figure 3 shows that more dependency for insured people should result in higher reserves. The dependent reserves always lay onto the independent reserves line until the contract is expired since the expected value of $T_{\overline{x y}}$ goes down when the correlations increase. The right panel of Figure 3 demonstrates that the ratio of the 
Table 7: Reserves and ratio of reserves of $\overline{A_{40: 40}}$ (Assumption: $T_{40}>t, T_{40}>t$ )

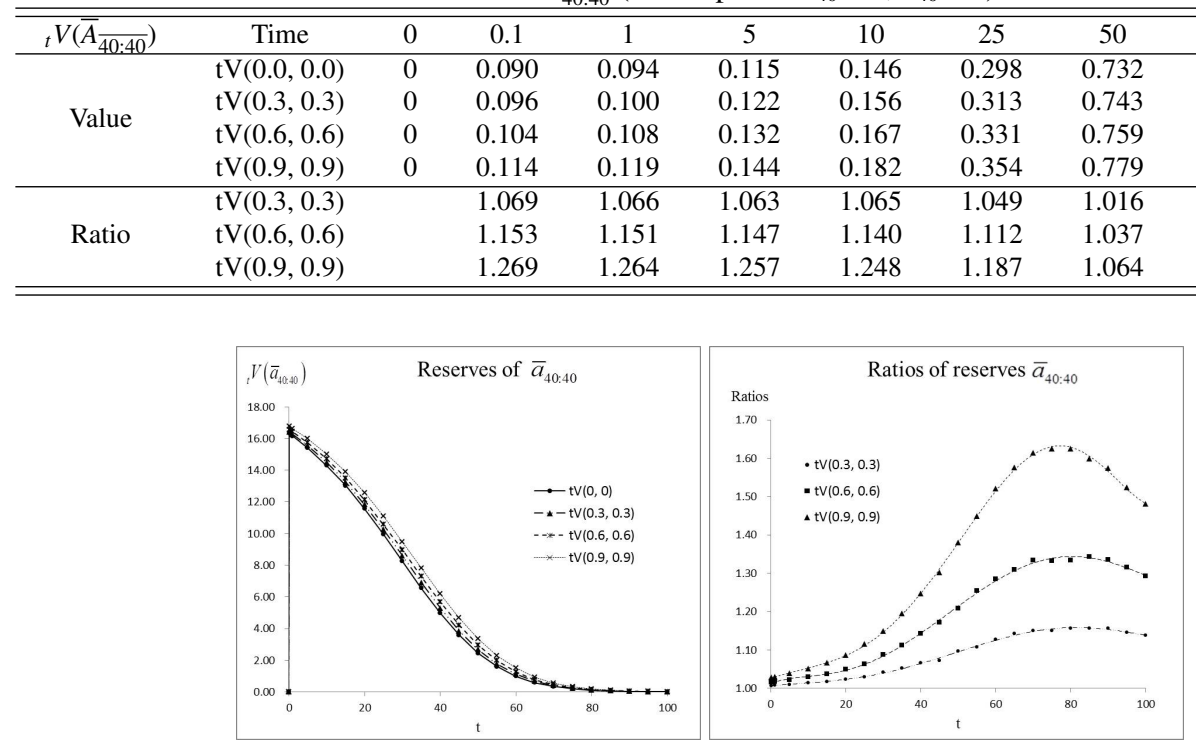

Figure 4: Reserves and ratio of reserves of $\bar{a}_{40: 40}$ (Assumption: $T_{40}>t, T_{40}>t$ )

Table 8: Reserves and ratio of reserves of ${ }_{t} V\left(\bar{a}_{x y}\right)$

\begin{tabular}{ccccccccccc}
\hline \hline${ }_{t} V\left(\bar{a}_{40: 40}\right)$ & Time & 0 & 0.1 & 1 & 5 & 10 & 25 & 50 & 75 & 100 \\
\hline \multirow{4}{*}{ Value } & $t V(0.0,0.0)$ & 0 & 16.313 & 16.146 & 15.391 & 14.288 & 9.954 & 2.445 & 0.201 & 0.011 \\
& $t V(0.3,0.3)$ & 0 & 16.413 & 16.261 & 15.542 & 14.488 & 10.250 & 2.682 & 0.231 & 0.013 \\
& $t V(0.6,0.6)$ & 0 & 16.563 & 16.425 & 15.727 & 14.715 & 10.579 & 2.955 & 0.268 & 0.015 \\
& $t V(0.9,0.9)$ & 0 & 16.765 & 16.625 & 15.984 & 15.015 & 11.096 & 3.375 & 0.327 & 0.017 \\
\hline \multirow{3}{*}{ Ratio } & $t V(0.3,0.3)$ & 1 & 1.006 & 1.007 & 1.010 & 1.014 & 1.030 & 1.097 & 1.150 & 1.138 \\
& $t V(0.6,0.6)$ & 1 & 1.015 & 1.017 & 1.022 & 1.030 & 1.063 & 1.208 & 1.332 & 1.292 \\
& $t V(0.9,0.9)$ & 1 & 1.028 & 1.030 & 1.039 & 1.051 & 1.115 & 1.380 & 1.625 & 1.480 \\
\hline \hline
\end{tabular}

corresponding dependent reserves to the independent reserve during the contract period. At the initial period of the contract, the ratio differences are big but become smaller when the insureds get older. Again, as the terminal value of reserves should be 1, all reserve ratios converge to 1 in the long run. Table 7 present some selected reserve values. In Table 7 (for example) the reserve of $\rho=0.6$ at time 5 is proportional to $114.7 \%$ compared with the value calculated under an independent assumption.

\subsection{Reserves of multiple life annuity: all of the insured alive}

A joint life annuity pays at a rate of 1 per year while all of the insureds are still alive, with its reserve calculated using equation (3.12). After the issue, the expected payment period shortens because mortality increases. This means that the reserves of the joint life annuity eventually goes to zero. Since the expectation of $T_{x y}$ increases as the correlation becomes higher, starting points of the reserves around time zero are high when its correlation is high.

In the right panel of Figure 4, unlike the joint life insurance case, the ratios of reserves increase from 1 and then decrease to 1, making a concave shape in their peaks. In the early time periods (although the reserves are different), as seen in the left panel, the large size of annuity values makes the ratios differences indistinguishable in the figure. The ratios are more distinct as the annuity reserves 


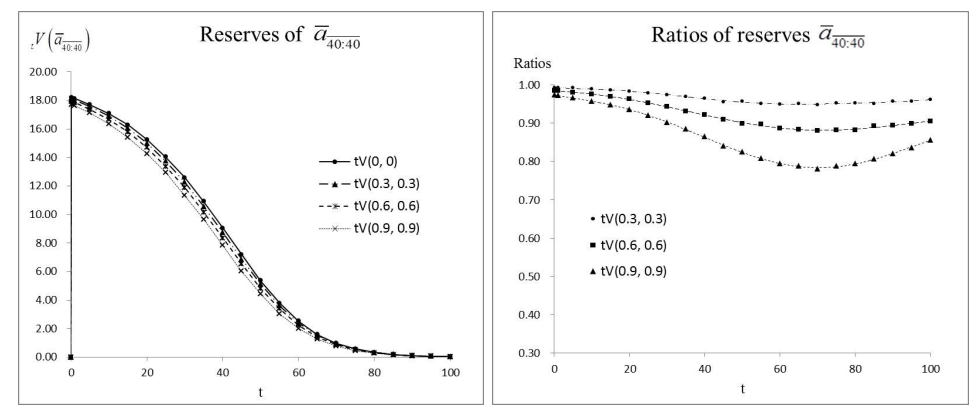

Figure 5: Reserves and ratio of reserves of $\bar{A} \overline{40: 40}$ (Assumption: $T_{40}>t, T_{40}>t$ )

Table 9: Reserves and ratio of reserves of ${ }_{t} V\left(\bar{a}_{\overline{x y}}\right)$

\begin{tabular}{ccccccccccc}
\hline \hline${ }_{t} V\left(\bar{a}_{\overline{40: 40}}\right)$ & Time & 0 & 0.1 & 1 & 5 & 10 & 25 & 50 & 75 & 100 \\
\hline \multirow{4}{*}{ Value } & $t V(0.0,0.0)$ & 0 & 18.204 & 18.119 & 17.705 & 17.076 & 14.041 & 5.362 & 0.581 & 0.038 \\
& $t V(0.3,0.3)$ & 0 & 18.079 & 17.995 & 17.562 & 16.886 & 13.749 & 5.134 & 0.553 & 0.037 \\
& $t V(0.6,0.6)$ & 0 & 17.929 & 17.835 & 17.369 & 16.665 & 13.371 & 4.823 & 0.512 & 0.035 \\
& $t V(0.9,0.9)$ & 0 & 17.720 & 17.622 & 17.115 & 16.352 & 12.928 & 4.427 & 0.457 & 0.033 \\
\hline \multirow{3}{*}{ Ratio } & $\mathrm{tV}(0.3,0.3)$ & 1 & 0.993 & 0.993 & 0.992 & 0.989 & 0.979 & 0.958 & 0.953 & 0.962 \\
& $t V(0.6,0.6)$ & 1 & 0.985 & 0.984 & 0.981 & 0.976 & 0.952 & 0.899 & 0.882 & 0.906 \\
& $t V(0.9,0.9)$ & 1 & 0.973 & 0.973 & 0.967 & 0.958 & 0.921 & 0.826 & 0.788 & 0.856 \\
\hline \hline
\end{tabular}

become small over time and indicate that the amount of expected annuity value are small and that the amount of differences after finding the ratio cannot be ignored anymore. Finally, at the terminal point of the contract, all reserves should be zero so the ratios of reserves go to 1 . The right panel of Figure 4 shows this tendency.

Let us look at the reserves of the last survivor annuity. Similar to the reserves of the joint life case, the reserves of the last survivor annuity decrease to zero over time. This is because; the expected payment period at the beginning of the contract is longer than that at the end of the contract. However, compared with the joint life annuity case, the reserves of the last survivor annuity decrease as the dependence becomes stronger. It is convenient for readers to think that the difference between $T_{x y}$ and $T_{\overline{x y}}$ becomes small as the correlation increases. For the ratios of reserves of the last survivor annuity (as seen in the right panel of Figure 5), they start from 1 and make a convex shape, finally going to 1 again as time goes to infinity. Table 9 presents some selected numbers.

Only one situation (where both are alive) needs to be considered when we analyze joint life insurance and annuity contract reserves. However, for the last survivor insurance and annuity also need to be accounted for when one of the insureds already has died at the valuation time.

\subsection{Reserves of multiple life insurance and annuity: one of the insureds already died}

In this subsection, we consider the reserve calculation of last survivor contracts under the assumption that one of the insureds has already died before the evaluation time $t$. In this case, the reserve calculation relies on the conditions like (3.3) or (3.4). Figure 6 shows the reserves of last survivor insurance and its ratio under the condition (3.3). When the future lifetimes of the insureds are mutually independent, the reserves of the contract at time $t,{ }_{t} V(0,0)$ are the same as the reserves of single whole life insurance. However, the reserves change if there exists a dependency between the mortalities of the insureds. Table 10 shows that when $\rho$ is 0.3 , the reserve value at time 0.5 is 0.349 , which is higher than the independent counterpart 0.162 . In the initial period, the starting reserves are quite different 

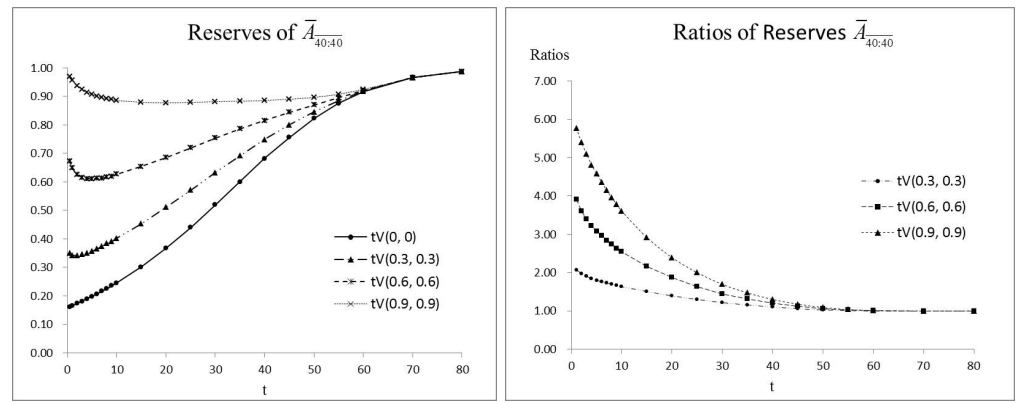

Figure 6: Reserves and ratios of reserves of $\bar{A} \overline{40: 40}$ (Assumption : $T_{40}>t, T_{40}<t$ )

Table 10: Reserves of multiple life insurance: one of the insured already die

\begin{tabular}{ccccccccccc}
\hline \hline${ }_{t} V(\bar{A} \overline{40: 40})$ & Time & 0.5 & 1 & 2 & 3 & 4 & 5 & 10 & 25 & 50 \\
\hline \multirow{3}{*}{ Value } & $t V(0.0,0.0)$ & 0.162 & 0.166 & 0.174 & 0.181 & 0.190 & 0.198 & 0.246 & 0.440 & 0.822 \\
& $t V(0.3,0.3)$ & 0.349 & 0.343 & 0.342 & 0.346 & 0.351 & 0.357 & 0.403 & 0.571 & 0.845 \\
& $t V(0.6,0.6)$ & 0.674 & 0.649 & 0.626 & 0.615 & 0.611 & 0.610 & 0.627 & 0.719 & 0.870 \\
& $t V(0.9,0.9)$ & 0.970 & 0.955 & 0.936 & 0.924 & 0.914 & 0.907 & 0.886 & 0.879 & 0.896 \\
\hline \multirow{3}{*}{ Ratio } & $t V(0.3,0.3)$ & 2.157 & 2.069 & 1.968 & 1.908 & 1.849 & 1.802 & 1.638 & 1.300 & 1.027 \\
& $t V(0.6,0.6)$ & 4.158 & 3.918 & 3.606 & 3.394 & 3.217 & 3.083 & 2.553 & 1.636 & 1.058 \\
& $t V(0.9,0.9)$ & 5.984 & 5.770 & 5.396 & 5.095 & 4.812 & 4.580 & 3.604 & 1.999 & 1.089 \\
\hline \hline
\end{tabular}

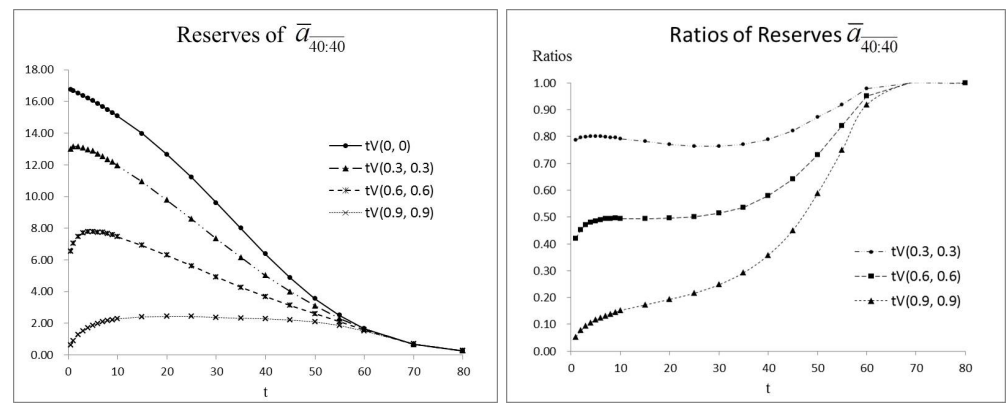

Figure 7: Reserves and ratios of reserves of $\overline{\bar{a}_{40: 40}}$ (Assumption : $T_{40}>t, T_{40}<t$ )

from the reserves under the condition that both insureds are alive.

When the parameter $\rho$ is 0.6 , the reserves at time 1 is 0.649 , which is higher than 0.108 in Table 7 which assumed that both insureds are still alive at time 1 . To understand this substantial difference, let us consider a correlated pair of random variables. Two random variables are expected to move together (each variable simultaneously realizes a small value) under a strong dependence. Therefore, when there is a high dependence between the future lifetimes of the insureds, the reserve of the last survivor insurance is close to 1 in the initial period of the contract. The terminal reserves are almost the same regardless of the dependency level, because the insureds are getting older and their mortalities increase, which means that the correlation effect on the reserves becomes negligible.

In the case of the last survivor annuity (as presented in Table 11 and Figure 7), the starting points of reserves are prone to decrease from the high value to zero as the dependency increases because it is likely that the remaining period of annuity becomes shorter than the independence case, given that the other insured is already dead. Opposite to the last survivor insurance case, the reserves of the last survivor annuity get smaller as the future lifetime random variables have a stronger correlation. Table 
Table 11: Reserves of multiple life annuity: one of the insured already die

\begin{tabular}{|c|c|c|c|c|c|c|c|c|c|c|}
\hline${ }_{t} V\left(\bar{a}_{\overline{40: 40}}\right)$ & Time & 0.5 & 1 & 2 & 3 & 4 & 5 & 10 & 25 & 50 \\
\hline \multirow{4}{*}{ Value } & $t V(0.0,0.0)$ & 16.760 & 16.690 & 16.530 & 16.370 & 16.200 & 16.040 & 15.090 & 11.210 & 3.553 \\
\hline & $t V(0.3,0.3)$ & 13.011 & 13.150 & 13.170 & 13.080 & 12.980 & 12.870 & 11.950 & 8.572 & 3.103 \\
\hline & $t V(0.6,0.6)$ & 6.526 & 7.025 & 7.484 & 7.694 & 7.785 & 7.791 & 7.451 & 5.613 & 2.597 \\
\hline & $t V(0.9,0.9)$ & 0.610 & 0.891 & 1.271 & 1.529 & 1.724 & 1.864 & 2.288 & 2.421 & 2.089 \\
\hline \multirow{3}{*}{ Ratio } & $t V(0.3,0.3)$ & 0.776 & 0.788 & 0.797 & 0.799 & 0.801 & 0.802 & 0.792 & 0.765 & 0.873 \\
\hline & $t V(0.6,0.6)$ & 0.389 & 0.421 & 0.453 & 0.470 & 0.480 & 0.486 & 0.494 & 0.501 & 0.731 \\
\hline & $t V(0.9,0.9)$ & 0.036 & 0.053 & 0.077 & 0.093 & 0.106 & 0.116 & 0.152 & 0.216 & 0.588 \\
\hline
\end{tabular}

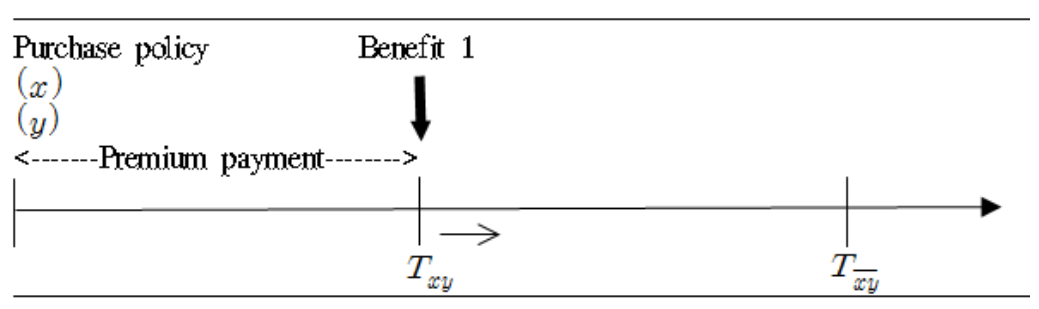

Figure 8: Cash flow and premium formula for Contract 1

11 shows that the reserves with $\rho=0.3$ at time 1 is 13.15 which is lower than 16.69 ; consequently, the reserves value under independence because if one of the two insureds has died in the initial period of the contract, the another is likely to die within a very short time.

\section{Contracts Analysis of Reserves under Dependent Assumption}

The purpose of this section is to offer a reserve analysis for more complicated insurance contracts which are combined by building blocks already studied in Section 4. The contract assumption used in the reserves calculation is the same as before: a man aged 40 and a woman aged 40 with a force of interest at 0.05 . In this section, we consider the case of dependence for reserveing, but with the premium derived from independence, which is denoted by ${ }_{t} V(\rho, 0)$. We consider four different multiple-life insurance contracts with various life statuses and payment patterns.

\subsection{Contract analysis 1}

Contract 1 is similar to the joint life insurance, but the insureds continuously pay premiums until the point of the first death; benefit 1 is payable at that time. Figure 8 presents the future cash flow of the analyzed contract. Using the equivalence principle of premium, under the independent assumption, the net premium at issue is given by

$$
\bar{P}=\frac{\bar{A}_{x y}}{\bar{a}_{x y}} .
$$

At time $t$, the prospective reserve, defined in (3.1), can be written as the expected value of the conditional random variable (3.2), that is,

$$
{ }_{t} V=\mathbb{E}\left[{ }_{t} L \mid T_{x y}>t\right]
$$

which can be explicitly written as

$$
{ }_{t} L=v^{\left(T_{x y}-t\right)}-\bar{P} \bar{a} \frac{}{T_{x y}-t} \mid T_{x y}>t .
$$




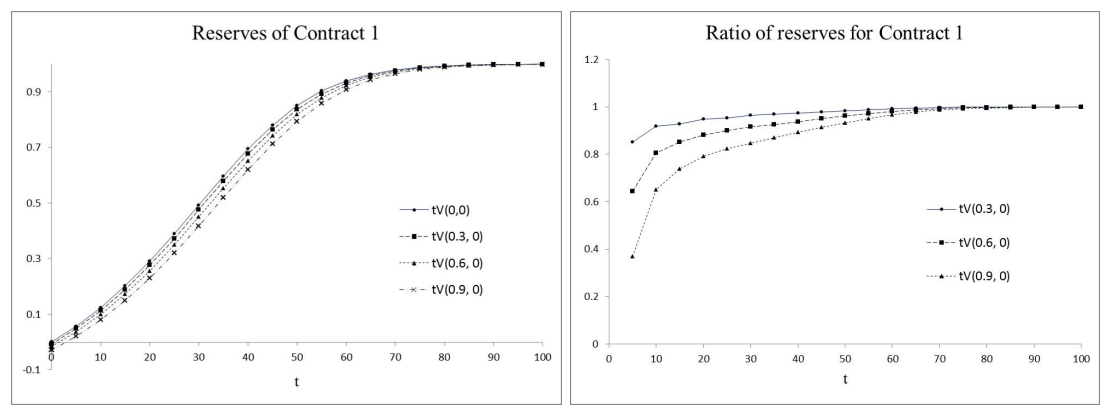

Figure 9: Reserves of Contract 1 at time $t$ (Assumption : $T_{40: 40}>t$ )

Table 12: Reserves of Contract 1 at time $t$ (Assumption : $T_{40: 40}>t$ )

\begin{tabular}{cccccccccc}
\hline \hline & Time & 0 & 0.1 & 5 & 10 & 25 & 50 & 75 & 100 \\
\hline \multirow{4}{*}{ Value } & $t V(0.0,0)$ & 0 & 0.001 & 0.056 & 0.123 & 0.389 & 0.851 & 0.988 & 0.999 \\
& $t V(0.3,0)$ & -0.008 & -0.007 & 0.048 & 0.113 & 0.371 & 0.836 & 0.986 & 0.999 \\
& $t V(0.6,0)$ & -0.016 & -0.014 & 0.036 & 0.099 & 0.350 & 0.819 & 0.984 & 0.999 \\
& $t V(0.9,0)$ & -0.029 & -0.029 & 0.021 & 0.080 & 0.321 & 0.792 & 0.980 & 0.999 \\
\hline \multirow{3}{*}{ Ratio } & $t V(0.3,0)$ & & -9.004 & 0.852 & 0.919 & 0.954 & 0.983 & 0.998 & 1 \\
& $t V(0.6,0)$ & & -19.389 & 0.644 & 0.806 & 0.900 & 0.962 & 0.996 & 1 \\
& $t V(0.9,0)$ & & -38.263 & 0.369 & 0.651 & 0.825 & 0.932 & 0.992 & 1 \\
\hline \hline
\end{tabular}

Hence, for Contract 1, we can express reserves as a linear function of three components: EPV of joint life insurance, the contract premium, and EPV of joint life annuity.

$$
\begin{aligned}
{ }_{t} V & =\mathbb{E}\left[v^{\left(T_{x y}-t\right)}-\bar{P} \bar{a}_{T_{x y}-t} \mid T_{x y}>t\right] \\
& =\bar{A}_{x+t, y+t}-\bar{P} \bar{a}_{x+t, y+t} .
\end{aligned}
$$

Figure 9 and Table 12 presents the reserve values (5.4) and their selected numbers, over different $\rho$ 's for both pricing and reserving sides. Figure 9 illustrates that the reserves tend to go down as $\rho$ gets larger. For example, in Table 12, when the independent reserve at time 5 is 0.056 , the dependent reserves are $0.048,0.036$ and 0.021 when each of the correlation parameter is $0.3,0.6$, and 0.9 , respectively. Note that a start point of the independent reserve is zero which is different from the reserves in, e.g., (3.8), where its loss random variable does not consider future incomes.

Moreover, the starting values of other dependent reserves have negative values. Lee et al. (2013) found that the value of $\bar{A}_{x y}$ decreases as the correlation of the insureds goes up. This is because the premium derived from independence is higher than that from a positive dependence for joint life insurance. The company has received more money than needed, and this explains negative reserves for early time periods.

\subsection{Contract analysis 2}

Contract 2 bears some resemblance to the last survivor insurance. As for Contract 1, the insureds continuously pay a premium until the first death occurs; however, benefit 1 will be paid at time of the second death. Figure 10 depicts the future cash flow of Contract 2. The equivalence principle of premium gives the net premium at issue as

$$
\bar{P}=\frac{\bar{A}_{\overline{x y}}}{\bar{a}_{x y}}
$$




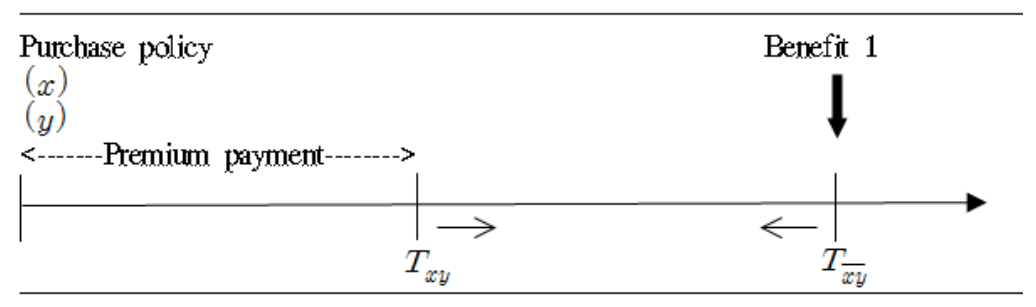

Figure 10: Cash flow and premium formula for Contract 2

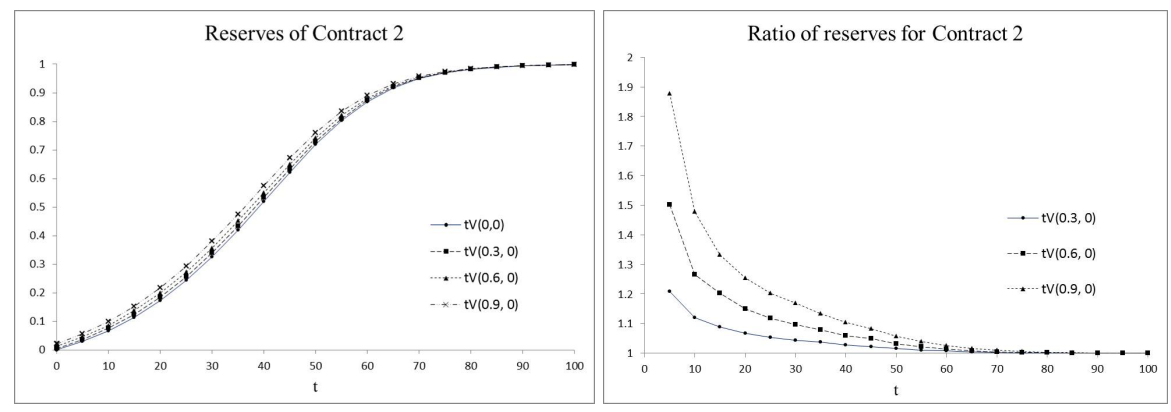

Figure 11: Reserves of Contract 2 at time $t$ (Assumption : $T_{40: 40}>t$ )

Table 13: Reserves of Contract 2 at time $t$ (Assumption : $T_{40: 40}>t$ )

\begin{tabular}{cccccccccc}
\hline \hline & Time & 0 & 0.1 & 5 & 10 & 25 & 50 & 75 & 100 \\
\hline \multirow{4}{*}{ Value } & $t V(0.0,0)$ & 0 & 0 & 0.030 & 0.068 & 0.243 & 0.718 & 0.970 & 0.998 \\
& $t V(0.3,0)$ & 0.005 & 0.006 & 0.036 & 0.076 & 0.256 & 0.730 & 0.971 & 0.998 \\
& $t V(0.6,0)$ & 0.012 & 0.013 & 0.045 & 0.086 & 0.272 & 0.742 & 0.973 & 0.998 \\
& $t V(0.9,0)$ & 0.021 & 0.022 & 0.057 & 0.100 & 0.293 & 0.760 & 0.975 & 0.998 \\
\hline \multirow{3}{*}{ Ratio } & $t V(0.3,0)$ & & 13.267 & 1.209 & 1.121 & 1.054 & 1.016 & 1.001 & 1 \\
& $t V(0.6,0)$ & & 29.999 & 1.501 & 1.266 & 1.119 & 1.033 & 1.003 & 1 \\
& $t V(0.9,0)$ & & 51.720 & 1.877 & 1.479 & 1.204 & 1.058 & 1.006 & 1 \\
\hline \hline
\end{tabular}

To calculate the reserve, we consider three cases written as

$$
\begin{aligned}
{ }_{t} L & =v^{\left(T_{\overline{x y}}-t\right)}-\bar{P} \bar{a} \frac{}{T_{x y}-t} \mid T_{x y}>t, \\
{ }_{t} L & =v^{\left(T_{x}-t\right)} \mid T_{x}>t, T_{y} \leq t, \\
{ }_{t} L & =v^{\left(T_{y}-t\right)} \mid T_{y}>t, T_{x} \leq t .
\end{aligned}
$$

Figure 11 illustrates the case where both insureds are alive at the valuation point. When the future lifetimes of the insureds are independent, the reserve starts from zero and goes to one over time. Note that the starting reserves increase, as the $\rho_{\text {reserves }}$ increases. According to the above premium equation, the premium of Contract 2 increases, as the correlation parameter has a high value. The premium the company received will be inadequate if the company receives the premium derived from independence assumption, but assumes that the future lifetimes of the insureds are correlated; consequently, the insurer loses money on this particular contract. The other two cases (5.7) and (5.8) can be similarly inferred from Section 4.4, and the details are omitted. 


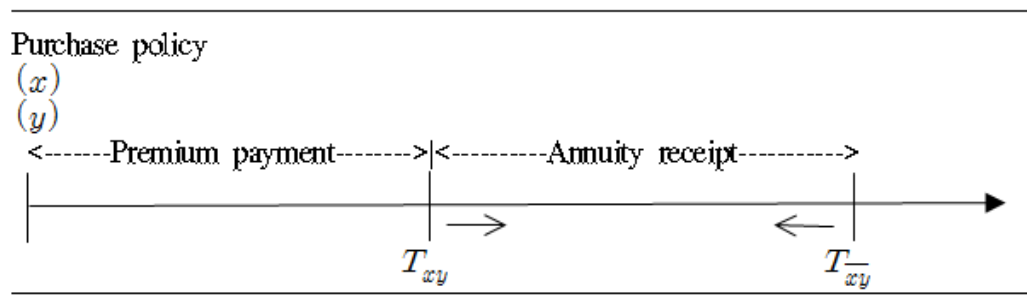

Figure 12: Cash flow and premium formula for Contract 3
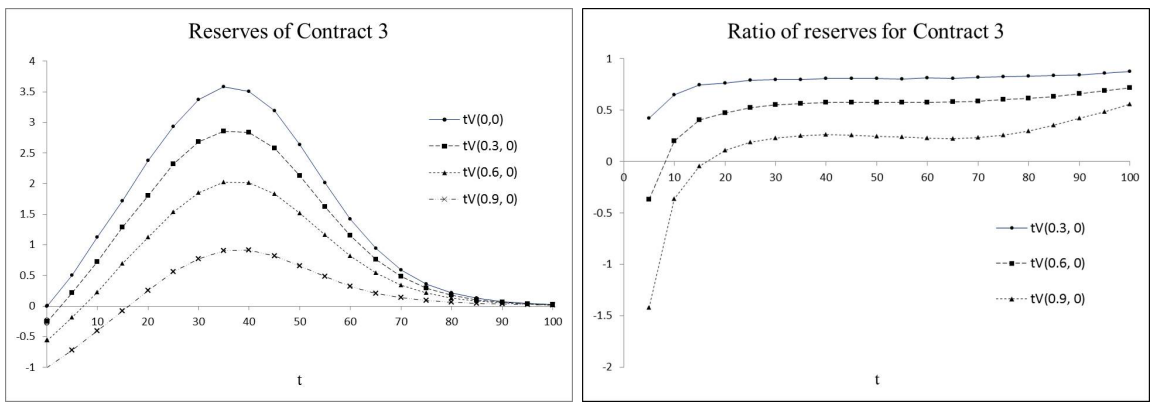

Figure 13: Reserves of Contract 3 at time $t$ (Assumption : $T_{40: 40}>t$ )

\subsection{Contract analysis 3}

The future cash flow of Contract 3 is depicted in Figure 12. In this case, the insureds pay premiums continuously until the first death, and an annuity is continuously paid after that by the insurer until the second death. From the equivalence principle of premium, the insurer's premium at issue is

$$
\bar{P}=\frac{\bar{a}_{\overline{x y}}-\bar{a}_{x y}}{\bar{a}_{x y}} .
$$

The loss random variable should be distinguished by the joint life status. The three cases can be written as

$$
\begin{aligned}
{ }_{t} L & =\left(\bar{a}_{\overline{T_{x y}-t} \mid}-\bar{a} \frac{T_{x y}-t}{}\right)-\bar{P} \bar{a}_{\overline{T_{x y}-t} \mid} \mid T_{x y}>t, \\
{ }_{t} L & =\bar{a} \frac{{ }_{T}-t}{} \mid T_{x}>t, T_{y} \leq t, \\
{ }_{t} L & =\bar{a} \frac{{ }_{T}-t \mid}{T_{y}} \mid T_{y}>t, T_{x} \leq t .
\end{aligned}
$$

Let us analyze the first case. Figure 13 illustrates the reserves under the assumption that both insureds are alive at the evaluation point. The top line of the four lines in the graph means the independent reserves which calculated under the independent assumption in pricing and reserving. This independent reserve starts from zero and goes back to zero making a "concave down" shape during the contract period. The starting point should be zero because of the premium calculated by equivalence premium principle. To understand the shape of the curve, let us state the reserves at time $t$ given that both the insured are still alive.

$$
\begin{aligned}
{ }_{t} V & =\mathbb{E}\left[\left(\bar{a}_{\overline{T_{\overline{x y}}-t} \mid}-\bar{a} \frac{}{T_{x y}-t}\right)-\bar{P} \bar{a}_{\overline{T_{x y}-t} \mid} \mid T_{x y}>t\right] \\
& =\left(\bar{a}_{\overline{x+t: y+t}}-\bar{a}_{x+t: y+t}\right)-\bar{P} \bar{a}_{x+t: y+t} .
\end{aligned}
$$


Table 14: Reserves of Contract 3 at time $t$ (Assumption : $T_{40: 40}>t$ )

\begin{tabular}{rcrrrrrrrc}
\hline \hline \multirow{4}{*}{ Value } & Time & \multicolumn{1}{c}{0} & \multicolumn{1}{c}{0.1} & \multicolumn{1}{c}{5} & 10 & \multicolumn{1}{c}{25} & 50 & 75 & 100 \\
& $t V(0.0,0)$ & 0 & 0.004 & 0.506 & 1.125 & 2.930 & 2.636 & 0.357 & 0.026 \\
& $t V(0.3,0)$ & -0.256 & -0.254 & 0.212 & 0.727 & 2.323 & 2.130 & 0.294 & 0.023 \\
& $t V(0.6,0)$ & -0.563 & -0.554 & -0.187 & 0.223 & 1.538 & 1.517 & 0.215 & 0.019 \\
& $t V(0.9,0)$ & -1.006 & -1.001 & -0.722 & -0.409 & 0.556 & 0.652 & 0.092 & 0.014 \\
\hline \multirow{3}{*}{ Ratio } & $t V(0.3,0)$ & & -68.445 & 0.419 & 0.646 & 0.793 & 0.808 & 0.822 & 0.874 \\
& $t V(0.6,0)$ & & -149.278 & -0.369 & 0.198 & 0.525 & 0.576 & 0.601 & 0.719 \\
& $t V(0.9,0)$ & & -269.572 & -1.425 & -0.363 & 0.190 & 0.247 & 0.258 & 0.556 \\
\hline \hline
\end{tabular}

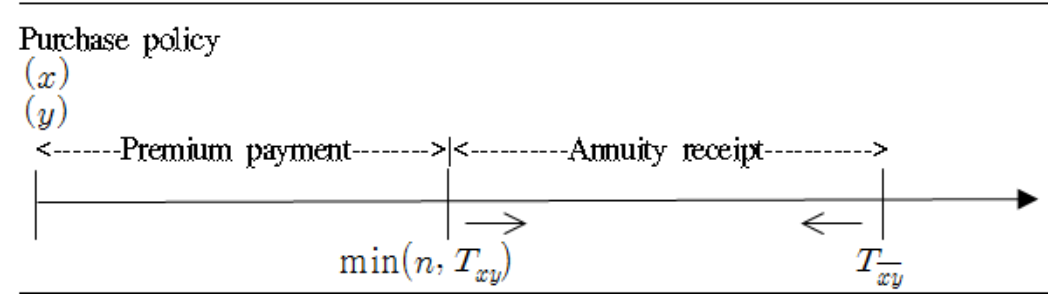

Figure 14: Cash flow and premium formula for Contract 4

For instance, let us assume that the insurer is at time 10, 40 and 60, where the reserves are given by

$$
\begin{aligned}
& { }_{10} V=\left(\bar{a}_{\overline{x+10: y+10}}-\bar{a}_{x+10: y+10}\right)-\bar{P} \bar{a}_{x+10: y+10}, \\
& { }_{40} V=\left(\bar{a} \overline{\overline{x+40: y+40}}-\bar{a}_{x+40: y+40}\right)-\bar{P} \bar{a}_{x+40: y+40}, \\
& { }_{60} V=\left(\bar{a}_{\overline{x+60: y+60}}-\bar{a}_{x+60: y+60}\right)-\bar{P} \bar{a}_{x+60: y+60} .
\end{aligned}
$$

We can separate the reserves at time $t$ into benefits and premium incomes. Compared to the reserve at time 10 , the reserve at time 40 is bigger because the income part of (5.15) is smaller than that of (5.14). However, the reserves at time 60 is small compared to the reserve of time 40 . The benefit part of (5.16) is much smaller than that of (5.15) despite the similar income amount.

The expected present value of the annuity related to the premium payment period, $\bar{a}_{x+t: y+t}$, decrease as $t$ gets larger. This makes the reserve decrease since it has a negative coefficient in the reserves calculation. For this reason, the reserves escalates while time passes. However, after a certain point, $t$ is around 35 in our case, the reserve decreases although the value of annuity relating premium payment period goes to zero. This is because the value of the annuity relating benefit annuity also decrease. The insurer would not need to hold much reserve when the insureds get old after a certain amount of time passes because both the premium payment period and the benefit annuity period become short. The reserves for other cases are skipped, as it is easily inferred from Section 4.4, which contains the reserve of the annuity given condition where one of the insureds has died prior to $t$.

\subsection{Contract analysis 4}

In this subsection, we will analyze a more realistically adjusted version of Contract 3 . Let us suppose that there is a couple who wants to receive an annuity after their retirement point $n$, or the time of death of spouse occur. To meet their needs, insurance companies can modify the terms of Contract 3 which are especially related to the premium payment period. This modified contract is called Contract 4 and Figure 14 depicts its cashflow. The insureds pay premiums continuously until the first death or $n$ years, whichever comes first. This can be written as $\min \left(T_{x y}, n\right)$. After the premium payment, an 

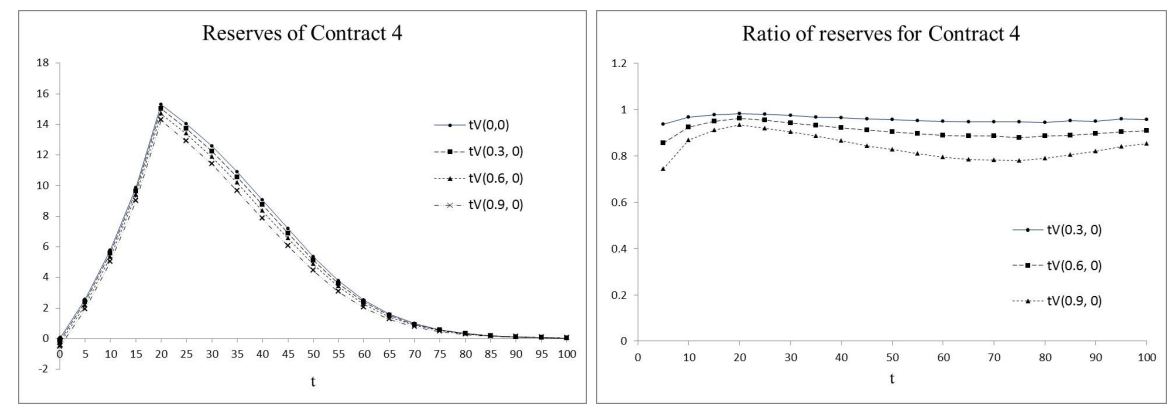

Figure 15: Reserves of Contract 4 at time $t$ (Assumption : $T_{40: 40}>t$ )

Table 15: Reserves of Contract 4 at time $t$ (Assumption : $T_{40: 40}>t$ )

\begin{tabular}{cccccccccc}
\hline \hline \multirow{4}{*}{ Value } & Time & 0 & 0.1 & 5 & 10 & 15 & 20 & 40 & 60 \\
& $t V(0.0,0)$ & 0 & 0.056 & 2.548 & 5.763 & 9.869 & 15.277 & 9.059 & 2.519 \\
& $t V(0.3,0)$ & -0.123 & -0.080 & 2.389 & 5.574 & 9.649 & 15.011 & 8.746 & 2.393 \\
& $t V(0.6,0)$ & -0.286 & -0.241 & 2.178 & 5.329 & 9.366 & 14.693 & 8.339 & 2.241 \\
& $t V(0.9,0)$ & -0.542 & -0.474 & 1.895 & 4.997 & 8.993 & 14.279 & 7.837 & 2.004 \\
\hline \multirow{3}{*}{ Ratio } & $t V(0.3,0)$ & & -1.434 & 0.938 & 0.967 & 0.978 & 0.983 & 0.965 & 0.950 \\
& $t V(0.6,0)$ & & -4.318 & 0.855 & 0.925 & 0.949 & 0.962 & 0.920 & 0.890 \\
& $t V(0.9,0)$ & & -8.515 & 0.744 & 0.867 & 0.911 & 0.935 & 0.865 & 0.795 \\
\hline \hline
\end{tabular}

annuity is continuously paid by an insurer until the second death. Many retirement annuity plans have similar cash flow structures. Let us assume that a couple both aged 40 purchase the above insurance with $n=20$ years. Using the equivalence principle of premium, the insurer can determine a premium at issue by

$$
\bar{P}=\frac{\bar{a}_{\overline{x y}}-\bar{a}_{x y: \bar{n} \mid} .}{\bar{a}_{x y: \bar{n} \mid}} .
$$

The loss random variable can be divided into three cases; however, we focus on the case that both insureds are alive, in which case,

$$
{ }_{t} L=\left(\bar{a} \frac{}{T_{\overline{x y}}-t} \mid-\bar{a} \frac{}{\min \left(T_{x y}-t, n-t\right)}\right)-\bar{P} \bar{a} \frac{}{\min \left(T_{x y}-t, n-t\right)} \mid T_{x y}>t,
$$

where $t<n$, and

$$
{ }_{t} L=\left(\bar{a} \frac{\overline{T_{x y}}-t \mid}{}-\bar{a} \frac{}{T_{x y}-t}\right) \mid T_{x y}>t,
$$

where $t>n$. The other cases can be easily inferred from the previous section.

Figure 15 and Table 15 are calculated under the assumption that both insureds are alive. In comparison to Contract 3, Contract 4 has adjusted premium payment period. The reserves of Contract 4 can be analyzed by two periods: One before the premium payment has not yet finished, and the other period after the annuity initiates. Under the contract policy, after 20 years from the issue, the insurer must pay the annuity to the insureds regardless of the joint life status (unless both are dead by then). Therefore, the reserves steeply grow for the first 20 years for paying the benefit annuity. Once the $20^{\text {th }}$ year passes, the reserves of this contract are similar to the reserves of the last survivor annuity in Section 4.3. 


\section{Conclusion}

This paper re-confirms identity (2.11), an important general relationship of the multiple life random variables suggested in Youn et al. (2002), through a Gaussian copula model. As reserves are the expected values of conditional future loss random variables, the dependence between two lives materially affect multiple life reserves. Various reserves of multiple life insurance contracts are analyzed in the presence of dependence between the insureds' future lifetimes. In particular, the dependence parameter on pricing and reserving sides are separately considered in reserve calculations because of their different implications and consequences.

In the cases of the single premium contracts, we find the reserves of joint life insurance decrease as the dependence of the insured increases, while the reserves of last survivor nsurance increase on strong dependence. The situation is reversed in the case of single premium annuity contracts where we obtain higher reserves for joint life annuities as dependence increases; however, the reserves of last survivor annuities produce lower values. Using these standard results, we further analyze the reserves of various multiple insurance contracts with a level premium.

This paper suggests different correlation structures for pricing and reserving; however, they are still assumed constant during the contract period. It may be more realistic to assume that the dependency level is a function of time $t$. We intend to explore this topic with real datasets in future research.

\section{References}

Bowers, N. L., Gerber, H. U., Hickman, J. C., Jones, D. A. and Nesbitt, C. J. (1997). Actuarial Mathematics, Society of Actuaries, Schaumburg (Ill).

Carriere, J. F. (1994). An investigation of the Gompertz law of mortality, Actuarial Research Clearing House, 2, 161-177.

Cherubini, U., Luciano, E. and Vecchiato, W. (2004). Copula Methods in Finance, John Wiley \& Sons, Hoboken, NJ.

de Jong, P. (2012). Modeling dependence between loss triangles, North American Actuarial Journal, 16, 74-86.

Dickson, D. C. M., Hardy, M. R. and Waters, H. R. (2009). Actuarial Mathematics for Life Contingent Risks, Cambridge University Press, Cambridge, UK.

Fang, H.-B., Fang, K.-T. and Kotz, S. (2002). The meta-elliptical distributions with given marginals, Journal of Multivariate Analysis, 82, 1-16.

Frees, E. W., Carriere, J, and Emiliano, V. (1996). Annuity Valuation with Dependent Mortality, The Journal of Risk and Insurance, 63, 229-261.

Frees, E. W. and Valdez, E. A. (1998). Understanding relationships using copula, North American Actuarial Journal, 2, 1-25.

Klugman, S. A., Panjer, H. H. and Willmot, G. E. (2010). Loss Models: From Data to Decisions, Wiley, New York.

Kruskal, W. H. (1958). Ordinal measures of association, Journal of the American Statistical Association, 53, 814-861.

Lee, S., Baek, H.-Y. and Lee, H. (2013). Analysis of multiple life insurance using copula, Journal of the Korean Data Analysis Society, 15, 1933-1954.

Li, D. X. (2000). On default correlation: A copula function approach, Journal of Fixed Income, 9 , $43-54$.

Nelsen, R. B. (2006). An Introduction to Copulas, Springer, New York. 
Onken, A., Grünewälder, S., Munk, M. H. J. and Obermayer, K. (2009). Analyzing short-term noise dependencies of spike-counts in macaque prefrontal cortex using copulas and the flashlight transformation, PLOS Computational Biology, 5, e10000577.

Ross, S. M. (2006). A First Course in Probability, Pearson Prentice Hall, Upper Saddle River, NJ.

Scholzel, C. and Friederichs, P. (2008). Multivariate non-normally distributed random variables in climate research-introduction to the copula approach, Nonlinear Processes in Geophysics, 15, 761-772.

Shemyakin, A. E. and Youn, H. (2006). Copula models of joint last survivor analysis, Applied Stochastic Models in Business and Industry, 22, 211-224.

Shi, P. and Frees, E. W. (2011). Dependent loss reserving using copulas, Journal of the International Actuarial Association, 41, 449-486.

Simonič, A. (1990). Grupe Operatorjev s Pozitivnim Spektrom, Univerza v Ljubljani, FNT, Oddelek za Matematiko,

Sklar, A. (1973). Random variables, joint distribution functions, and copulas, Kybernetika, 9, 449460.

Wang, S. S. (1998). Discussions of papers already published, North American Actuarial Journal, 3, 137-141.

Youn, H., Shemyakin, A. and Herman, E. (2002). A Re-examination of the joint mortality functions, North American Actuarial Journal, 6, 166-170.

Zhang, L. and Singh, V. P. (2006). Bivariate flood frequency analysis using the copula method, Journal of Hydrologic Engineering, 11, 150-164. 